\title{
Supply Chain Management based on Blockchain: A Systematic Mapping Study
}

\author{
Youness Tribis ${ }^{1, *}$, Abdelali El Bouchti ${ }^{2,3}$, and Houssine Bouayad ${ }^{1}$ \\ ${ }^{1}$ Faculty of Technical Sciences, Hassan 1st University, Settat, Morocco \\ ${ }^{2}$ National School of Business and Management, Hassan 1st University, Settat, Morocco \\ ${ }^{3}$ Institute for Forecasting and Futuristics
}

\begin{abstract}
Groundbreakingly, blockchain technology (BCT) has gained widespread acceptance and importance in the last few years. Implemented in different areas of applications such as social and legal industries, finance, smart property, and supply chain networks. This technology assures immutability and integrity of data without the need of a third trusted party. Furthermore, BCT could guarantee a transparent and decentralized transaction system in businesses and industries. Even though general research has been done in the BCT, however, there is a lack of systematic analysis on current research challenges regarding how BCT is effectively applicable in supply chain management (SCM). A systematic literature review (SLR) of SCM based on blockchain does not exist yet. This work aims to explore and analyse the state-ofthe-art on the BCT applications for SCM. We synthesize existing evidence, and identify gaps, available in the literature. The survey uses a systematic mapping study (SMS) method to examine 40 extracted primary studies from scientific databases.
\end{abstract}

Keywords: blockchain, supply chain, supply chain management, systematic mapping study,

\section{Introduction}

To improve the supply chains performance for many industries and provide new supply chain management (SCM) solutions, some systematic literature review (SLR) on SCM have, recently, demonstrated the importance of information and communication technology (ICT) ([1], [2], [3], [4] and [5]), but without focusing on blockchain technology (BCT).

The BCT has been generating interesting research areas because of its innovative characteristics that provide efficient solutions for the current gaps related to several supply chains industries. Indeed, existing SLR on blockchain conducted until now did not address such topic linked to the blockchain application for SCM. For example, a SLR performed by BOJANA KOTESKA et al. [6], Stefan Seebacher and Ronny Schüritz [7], and SMS established by Yli-Huumo J, et al. [8], did not cover blockchain application for SCM that should be possible to map out the current status of research area.

Blockchain is a decentralized transaction and data management technology firstly designed, by Satoshi Nakamoto, for Bitcoin cryptocurrency [9]. Based on the literature, the blockchain definition was synthesized as a distributed database, which is shared among and agreed upon a peer-to-peer network. It consists of a linked sequence of blocks, holding timestamped transactions that are secured by public-key cryptography and verified by the network community. Once an element is appended to the blockchain, it cannot be altered, turning a blockchain into an immutable record of past activity [7].

Trust and decentralization were identified as the two key BCT characteristics, which are closely connected and interrelated [7].

The remaining parts of the paper are structured as follows: In Section 2, we describe the applied research methodology and the process of collecting relevant research papers. Section 3 presents the results of the collected papers and the classification mechanism extracted from data. Section 4 discusses the study and answers the research questions. Section 6 presents the limitations of this mapping study, and Section 7 concludes the paper.

\section{Research methodology}

In this study, we follow the SMS process, described by Petersen et al. [10], to explore the existing studies related to BCT applied for SCM. We also use guidelines for a SLR described by Kitchenham and Charters [11] to search for relevant papers which covered the literature from all years to 2018. The results of the SMS would help us to identify and map research areas related to BCT based SCM and possible research gaps. The SMS process

\footnotetext{
Corresponding author: y.tribis@uhp.ac.ma
} 
is presented in Figure 1 and consists of five process steps and outcomes.

\section{Process Steps}

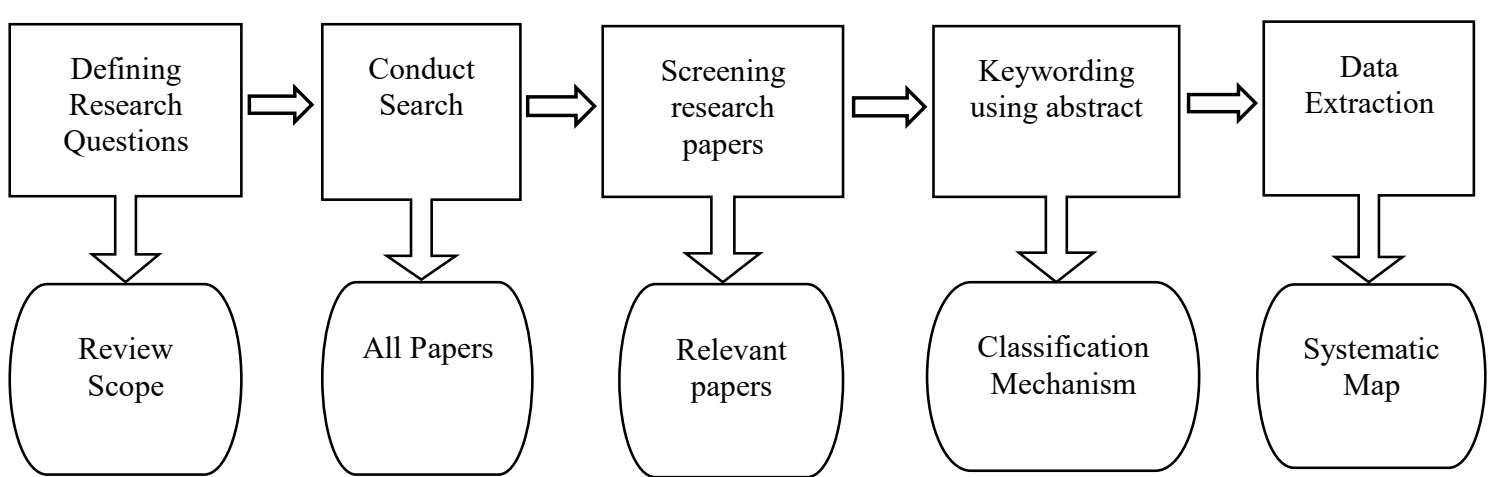

of understanding based on these keywords. We used the keywords to group and form classes for the mapping the studies. After that, we read all the selected papers and updated the categories or created new ones, if the paper exposed something new. The result

\section{Outcome}

Fig. 1. The systematic mapping process

We defined three research questions that form the basis for the review:

- RQ1: What research topics have been addressed in existing research on SCM based on BCT?

- RQ2: What are the benefits would BCT bring to resolve the current problems in the supply chain industries?

- RQ3: What are the current research gaps in SCM related to BCT?

To search the relevant papers on the research topic, we decided to use every time the terms "supply chain" and "blockchain" in the search string. After designing and testing the search protocol, we chose the scientific databases, for the searches. The search was conducted on January 2018 and updated on May 2018.

A screening process was composed of four filters, in order to select the most suitable results. Firstly, we screened all papers based on their types and titles similarity to exclude duplicates, technical reports and notes. Secondly, we screened the papers based on their titles and excluded studies that were not relevant to the scope of this mapping study. Thirdly, the authors read the abstracts of every paper that passed the previous filter. Finally, the authors read the full text of all included papers in the third filter.

To screen each paper, we used inclusion and exclusion criteria. We exclude the following types of papers: (1) papers that were duplicates, (2) papers that were technical reports and thesis, (3) papers without full text availability (4) papers where the main language was not English, (5) papers that had some other meaning than blockchain used in SCM, and (6) the phrases of at least one of the search terms didn't be included in the heading, keywords or abstract of the paper.

The next stage in a SMS is keywording as defined by Petersen et al. [10]. Firstly, we read the abstract and identified keywords and concepts that represent the contribution of the paper. Next, we develop a higher level was a systematic map of collected categories designed from all the relevant papers.

The data extraction form should be designed to collect all the information needed to address the research questions of this mapping study. The following information, was extracted from each study; Title of the paper, Name of the author(s), Country of authors, Type of the publication (e.g. conference/journal), Abstract, Methodology, Research questions and Major study findings.

\section{Results}

Based on the extracted data, the search and selection results are presented in Figure 2. As a result, 40 primary papers have been included in this study.

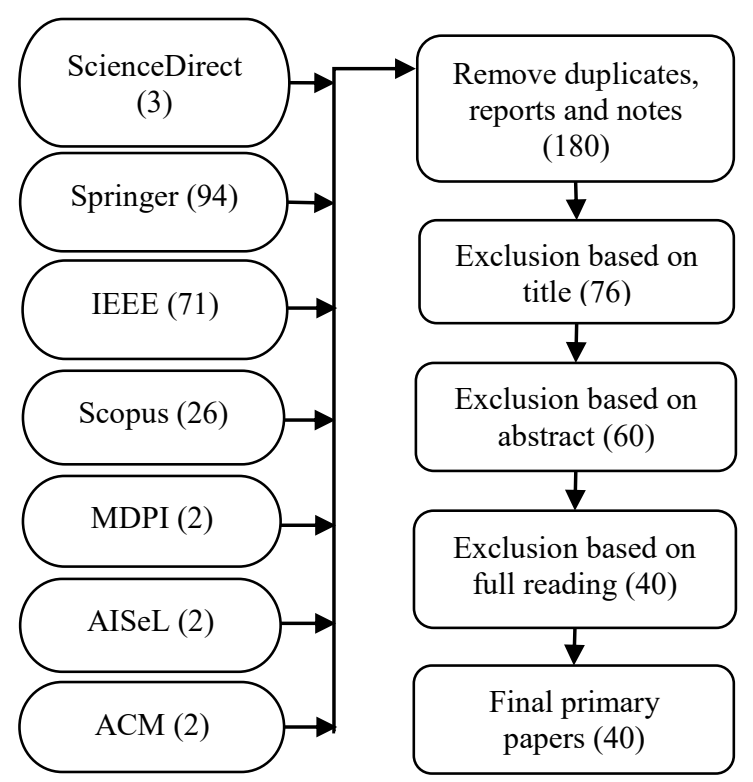

Fig. 2. Search and selection process of the papers. 
Considering the publication year, the distribution of the primary studies was shown in Figure 3. Remarkably, all the selected papers were published after the year 2015 . This demonstrates that this research area is a modern and novel one. When zoom in at the publication year distribution, out of all the selected papers, 2 papers $(5.71 \%)$ were published in 2016,22 papers $(62.86 \%)$ in 2017 and 16 papers (45.71\%) in April 2018. Thus, the number of publications increases each year, which reflects the rise of interest in $\mathrm{BCT}$.

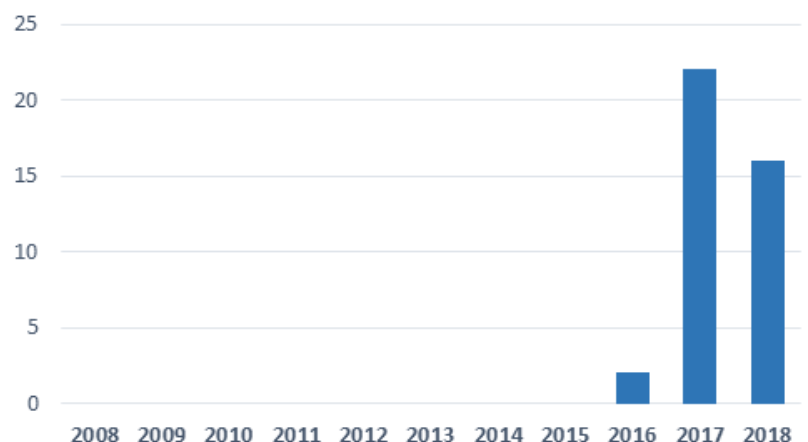

Fig. 3. Publication year of the selected primary papers.

Figure 4 illustrates the geographical distribution of the primary papers. Dispersed at 16 countries, this geographical distribution shows that BCT has gained research attention around the world. The major number of papers $12(34.29 \%)$ were published by universities or companies in the USA. After this, the second position was occupied by Switzerland and China with 5 papers $(14.29 \%)$. The rest of the countries had two or less papers published.

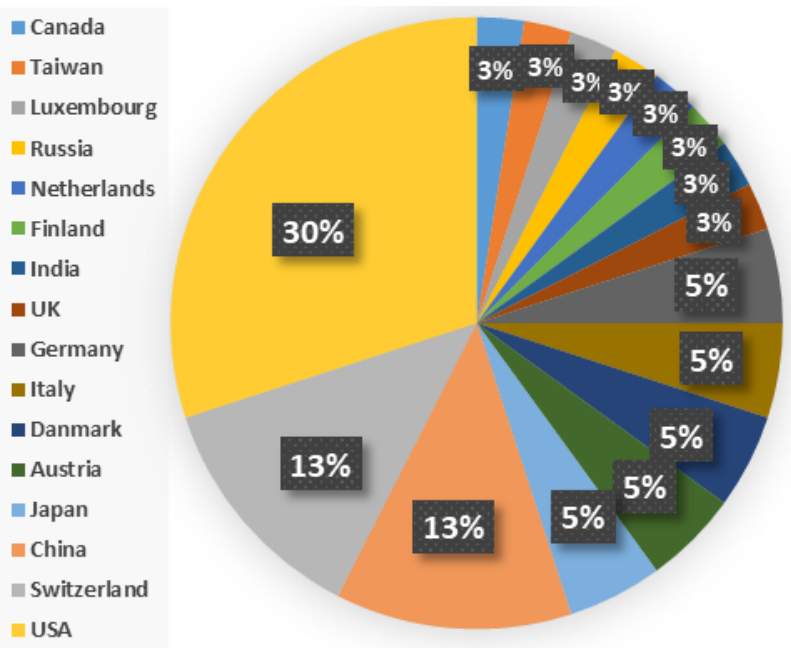

Fig. 4. Geographic distribution of the selected primary papers.

The publication channel distribution was presented in Figure 5. Most of the papers were published in journals (19) $(45.29 \%)$ and conference (12) $(34.29 \%)$. The rest of the papers were published in book section (5) $(14.29 \%)$, workshop (3) $(8.57 \%)$, or in symposium (1) $(2.86 \%)$.

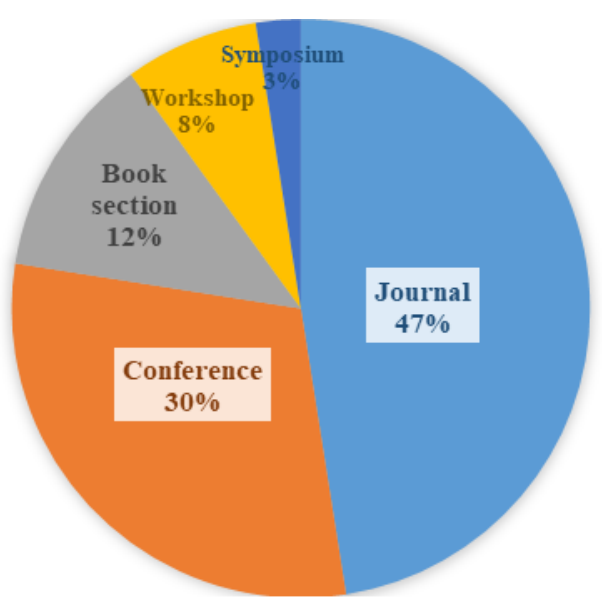

Fig. 5. Publication type.

In addition, Table 1 displays the global list of publication channel of the selected papers.

The classification mechanism, presented in a bubble plot (Figure 6), assembled two facets. One facet structured the topic in terms of the research thematic. The other considered the research type as described by Wieringa et al. [12].

Within the research topic facet, we summarize the primary studies on 10 main research topics. We identified one thematic, supply chain traceability, that represent the majority of topics (17 papers, $42.5 \%$ ) and focus on some special supply chain industries such as food supply chain (3 papers) and pharma supply chain (3 papers). It has really been the overall interest of researchers.

Furthermore, some topics present a relevant amount of entries in this analysis, such as information security of SCM system (7 papers, 17.5\%) and supply chain finance (7 papers) were the second important topics. In addition, we have pointed out topics in which new solutions are required; it is the case of supply chain quality management, product ownership management, additive manufacturing and agricultural supply chain.

According to the research category, the majority of these papers $(45.71 \%)$ were solution proposal papers (16 papers) which aim to propose a new blockchain based frameworks related to several supply chain industries. We realize that currently, validation and evaluation research are weakly addressed in SCM based on blockchain papers. We also appreciate that researchers are not concerned about expressing opinions and experience reports on their personal experience.

\section{Discussion}

Besides the identified research topics, the SMS showed that a majority of research was focused in three main themes: physical traceability of supply chains (17 papers), information security of SCM system (7 papers), and supply chain finance ( 7 papers). The rest of the identified topics were gained a few interests of the scholars. 
Table 1. Publication channels

\begin{tabular}{|c|c|c|}
\hline & Publication channels & Reference \\
\hline IJIM & International Journal of Information Management & [13] \\
\hline ICEBE & International Conference on e-Business Engineering & {$[14]$} \\
\hline AISC & Advances in Intelligent Systems and Computing & [15] \\
\hline Information (Switz & erland) & [16] \\
\hline IEEE Access & & [17] \\
\hline EODS & Expert Opinion on Drug Safety & [18] \\
\hline ICSSSM & $\begin{array}{l}\text { International Conference on Services Systems and Services } \\
\text { Management }\end{array}$ & [19] [20] \\
\hline IEEE Software & & {$[21]$} \\
\hline ICIEEM & $\begin{array}{l}\text { IEEE International Conference on Industrial Engineering and } \\
\text { Engineering Management }\end{array}$ & [22] \\
\hline WiMob & $\begin{array}{l}\text { IEEE International Conference on Wireless and Mobile } \\
\text { Computing, Networking and Communications }\end{array}$ & [23] \\
\hline Telecommunicatio & ns Policy & {$[24]$} \\
\hline ISINSM & $\begin{array}{l}\text { IFIP/IEEE International Symposium on Integrated Network and } \\
\text { Service Management }\end{array}$ & [25] \\
\hline JCST & Journal of Computer Science and Technology & {$[26]$} \\
\hline ICCCN & $\begin{array}{l}\text { International Conference on Computer Communication and } \\
\text { Networks }\end{array}$ & {$[27]$} \\
\hline Springer, Cham & & $\begin{array}{l}{[28][29][30]} \\
{[31]}\end{array}$ \\
\hline ISAFM & Intelligent Systems in Accounting, Finance and Management & [32] \\
\hline JIIS & Journal of Intelligent Information Systems & [33] \\
\hline HICSS-50 & Hawaii International Conference on System Sciences & [34] \\
\hline JMCC & Journal of Materials Chemistry C & [35] \\
\hline (AISeL) & AMCIS Workshops & {$[36]$} \\
\hline CBI & IEEE Conference on Business Informatics & [37] \\
\hline ICDCSW & $\begin{array}{l}\text { IEEE International Conference on Distributed Computing Systems } \\
\text { Workshops }\end{array}$ & [38] \\
\hline JPSM & Journal of Purchasing and Supply Management & [39] \\
\hline FGCS & Future Generation Computer Systems & {$[40]$} \\
\hline $\mathrm{FAS} * \mathrm{~W}$ & $\begin{array}{l}\text { IEEE International Workshops on Foundations and Applications } \\
\text { of Self* Systems }\end{array}$ & [41] \\
\hline Palgrave Macmilla & n, Cham & [42] \\
\hline NTMS & $\begin{array}{l}\text { IFIP International Conference on New Technologies, Mobility } \\
\text { and Security }\end{array}$ & [43] \\
\hline Logistics (MDPI) & & {$[44]$} \\
\hline ISAFM & Intelligent Systems in Accounting, Finance and Management & {$[45]$} \\
\hline LNICST & $\begin{array}{l}\text { Lecture Notes of the Institute for Computer Sciences, Social- } \\
\text { Informatics and Telecommunications Engineering }\end{array}$ & [46] \\
\hline JEFC & Journal of Excipients and Food Chemicals & [47] \\
\hline ICHNAS & $\begin{array}{l}\text { IEEE International Conference on e-Health Networking, } \\
\text { Applications and Services (Healthcom) }\end{array}$ & [48] \\
\hline BISE & Business \& Information Systems Engineering & [49] \\
\hline ACM CSG & ACM Conference on Supporting Groupwork & {$[50]$} \\
\hline RCR & Resources, Conservation and Recycling & [51] \\
\hline ACM CENSS & ACM Conference on Embedded Network Sensor Systems & {$[52]$} \\
\hline
\end{tabular}

Regarding the traceability thematic, there are two important fields that gain a more researcher's interest; the pharma supply chain ([41], [18], [34] and [36]) and food supply chain ([19], [20] and [22]). In addition, some specific subjects were introduced, such as, traceability of transportation dangerous good [31], aircraft's Part SCM [52], supply chain information system \& traceability [40], shipping domain [38] and cyber-physical systems for material flow analysis and life cycle assessment [39]. The others studies ([16], [33], [32], [21], and [26]) treat the traceability subject in general without focusing in particular supply chain domain. 


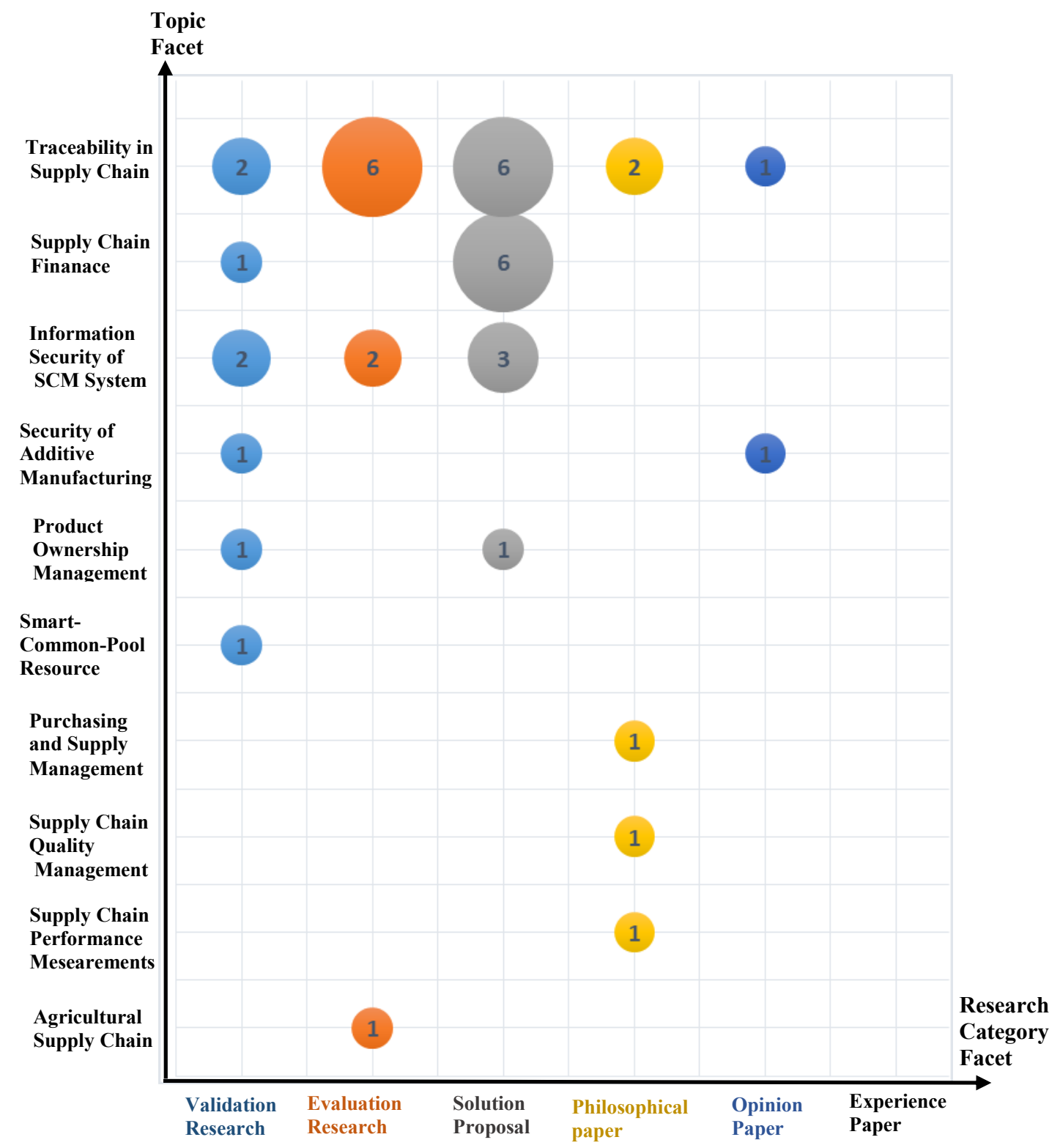

Fig. 6. A systematic map in the form of a bubble plot

We summarize the main benefits providing by this technology. In physical supply chain, the main BCT benefits for businesses are ensuring real-time traceability with trusted information and high level of reliability to all supply chain members with openness, transparency, reliability and security and providing pseudo real-time status of the shipment. BCT can increase the transparency of physical distribution process and eliminating the ability to cheat and provides each participant end-to-end visibility based on their level of permission. In addition, this technology could reduce operational costs by removing intermediaries' fees. For government, BCT could help to track, monitor and audit the supply chain and serving manufacturers to record the transactions in authenticity. For customers, BCT would enhancing the products quality and safety.
In the context of SCM information, the key BCT benefits for businesses are managing supply chain information more efficiently without being overly concerned about properly securing them, privacy immutability of data, public accessibility of records and access for diverse populations and locations. The government could receive more trusted information for better and focused inspections. For customers, BCT would guarantee public security of personal data.

In supply chain finance, BCT benefits for businesses are simplifying and making more agile and secure the trade finance commercial transactions among companies and financial institutions. Claims and contracts could be recorded onto a blockchain and validated by the network which allows all the stakeholders to identify the movements of funds between contractors, customers, and financial institutions. For government, auditing digital currency transactions help to raise the tax collection. For 
customers, BCT would bring more transparency and lower fees of transactions.

The majority of the identified gaps were related to external factors such as regulation and technical aspects. The first gap is the regulation conformance and legal barriers that limit the application of BCT. There is the lack of common standards for completing transactions. The second gap is the lack of adaptability and adoption. Many people are short of understanding of how it works that generate the large difficulty of bringing all the relevant parties together and convince the supply chain actors to adapt their old systems to the new blockchain based systems. The third gap is scalability and size. The majority of the proposed blockchain based frameworks were only tested on a limited scale in a laboratory environment; some challenges may emerge in scaling blockchains network with a large number of nodes. Furthermore, the sizes of the current blockchain applications are practically small. The fourth gap is high degree of computerization requirement. Indeed, many supply chain actors' in developing countries are not prepared to implement blockchain. The fifth gap is complexity and uncertainty. The latency of transactions that spend some hours to finish until all participants update their ledgers and the smart contract can be publicly accessible, but the data required for verification may or may not be accessible to all. The sixth gap is security and data integrity. The latency of transactions opens a window for cyber-attacks. Also, limited set of participants accessing to blockchain platform offering blockchain based solution, e.g. IBM and Ethereum, can cause more vulnerability to these blockchain based system. Thus, the security of these systems is impacted by that of these platforms. The seventh gap is the cost of implementation. For blockchain operation, the virtual network depended on a physical system for electricity, infrastructure, and hardware computing power. The eighth gaps are that the majority of the proposed frameworks were not evaluated to design systems for a real-world application, thus researchers should considerate the feasibility of the blockchain based solutions and verifying their applicability to the industry sectors.

\section{Limitations}

Publication bias, selection bias, imprecision in data extraction, and misclassification are the main limitations for this study. Publication bias is associated to the problem that is possible that some relevant studies were not chosen throughout the searching process. In fact, the search string included only the terms "blockchain" and "supply chain", there is a probability that not all the relevant research papers were found. Selection bias is assigned to the misinterpretation of to the criteria used to select the publications. Thus, we cannot guarantee that all relevant primary studies were selected. Imprecision in data extraction and misclassification are related to the risk that reviewers diverged when extracted the information.

\section{Conclusion}

This paper presents a systematic mapping study in order to map out all relevant research on SCM based on BCT. Guided by a set of research questions, the main motivation for this work was to identify research trends, open subjects, and gaps for improvement in this discipline. The results demonstrate that $42.5 \%$ of the papers focus on supply chain traceability based on blockchain, $17 \%$ of the papers address SCM information and $17 \%$ of the studies was conducted on the blockchain driven supply chain finance. The rest of the papers $(23.5 \%)$ treat other blockchain applications in SCM that need additional investigation, such as agricultural supply chain, security of additive manufacturing, product ownership management, common-pool resource management, purchasing and supply management, supply chain quality management, supply chain performance measurements. The large part of selected studies $(45.71 \%)$ is concentrating on proposing solutions of currents SCM challenges by designing new blockchain based frameworks. Nevertheless, many of the proposed frameworks-based solutions lack real performance evaluation on the industrial context.

\section{References}

[1] V. Maestrini, D. Luzzini, P. Maccarrone, and F. Caniato, "Supply chain performance measurement systems: A systematic review and research agenda,” Int. J. Prod. Econ., vol. 183, pp. 299-315, Jan. (2017).

[2] N. Zaheer and P. Trkman, "An information sharing theory perspective on willingness to share information in supply chains," Int. J. Logist. Manag., vol. 28, no. 2, pp. 417-443, May (2017).

[3] Q. Shi, X. Ding, J. Zuo, and G. Zillante, "Mobile Internet based construction supply chain management: A critical review," Autom. Constr., vol. 72, pp. 143-154, Dec. (2016).

[4] J. Volland, A. Fügener, J. Schoenfelder, and J. O. Brunner, "Material logistics in hospitals: A literature review," Omega, vol. 69, pp. 82-101, Jun. (2017).

[5] J. Barata, P. Rupino Da Cunha, and J. Stal, "Mobile supply chain management in the Industry 4.0 era: An annotated bibliography and guide for future research," J. Enterp. Inf. Manag., vol. 31, no. 1, pp. 173-192, Feb. (2018).

[6] B. KOTESKA, E. KARAFILOSKI, and A. MISHEV, "Blockchain Implementation Quality Challenges: A Literature." in SQAMIA 2017: 6th Workshop of Software Quality, Analysis, Monitoring, Improvement, and Applications. Belgrade, Serbia, September 11-13, (2017), vol. 1938, pp. 8:8

[7] S. Seebacher and R. Schüritz, "Blockchain Technology as an Enabler of Service Systems: A Structured Literature Review," in Za S., Drăgoicea M., Cavallari M. (eds) Exploring Services Science. 
IESS 2017. Lecture Notes in Business Information Processing, vol 279. Springer, Cham, (2017), pp. $12-23$.

[8] J. Yli-Huumo, D. Ko, S. Choi, S. Park, and K. Smolander, "Where Is Current Research on Blockchain Technology?-A Systematic Review," PloS One, vol. 11, no. 10, p. e0163477, (2016).

[9] S. Nakamoto, "Bitcoin: A Peer-to-Peer Electronic Cash System." [Online]. Available: https://bitcoin.org/bitcoin.pdf.

[10] K. Petersen, R. Feldt, S. Mujtaba, and M. Mattsson, "Systematic Mapping Studies in Software Engineering," in Proceedings of the 12th International Conference on Evaluation and Assessment in Software Engineering. EASE'08. Swinton, UK, UK: British Computer Society; (2008). p. 68-77.

[11] Kitchenham B (2007) Guidelines for performing Systematic Literature Reviews in Software Engineering, Version 2.3, EBSE Technical Report EBSE-2007-01, Keele University and University of Durham

[12] R. Wieringa, N. Maiden, N. Mead, and C. Rolland, "Requirements engineering paper classification and evaluation criteria: a proposal and a discussion," Requir. Eng., vol. 11, no. 1, pp. 102-107, Mar. (2006).

[13] N. Kshetri, “1 Blockchain's roles in meeting key supply chain management objectives," Int. J. Inf. Manag., vol. 39, pp. 80-89, (2018).

[14] S. Chen, R. Shi, Z. Ren, J. Yan, Y. Shi, and J. Zhang, "A Blockchain-Based Supply Chain Quality Management Framework," in 2017 IEEE 14th International Conference on e-Business Engineering (ICEBE), (2017), pp. 172-176.

[15] P.-Y. Chang, M.-S. Hwang, and C.-C. Yang, "A blockchain-based traceable certification system," Adv. Intell. Syst. Comput., vol. 733, pp. 363-369, (2018).

[16] H. Wu, Z. Li, B. King, Z. B. Miled, J. Wassick, and J. Tazelaar, "A distributed ledger for supply chain physical distribution visibility," Inf. Switz., vol. 8, no. 4, (2017)

[17] K. Toyoda, P. T. Mathiopoulos, I. Sasase, and T. Ohtsuki, "A Novel Blockchain-Based Product Ownership Management System (POMS) for AntiCounterfeits in The Post Supply Chain," IEEE Access, vol. 5, pp. 17465-17477, (2017).

[18] T. K. Mackey and G. Nayyar, "A review of existing and emerging digital technologies to combat the global trade in fake medicines," Expert Opin. Drug Saf., vol. 16, no. 5, pp. 587-602, (2017).

[19] F. Tian, "A supply chain traceability system for food safety based on HACCP, blockchain \& Internet of things," in the 14th International Conference on Services Systems and Services Management, ICSSSM 2017 - Proceedings, (2017).

[20] F. Tian, "An agri-food supply chain traceability system for China based on RFID \& blockchain technology," in the 2016 13th International
Conference on Service Systems and Service Management, ICSSSM 2016, (2016).

[21] Q. Lu and X. Xu, "Adaptable Blockchain-Based Systems: A Case Study for Product Traceability," IEEE Softw., vol. 34, no. 6, pp. 21-27, (2017).

[22] D. Tse, B. Zhang, Y. Yang, C. Cheng, and H. Mu, "Blockchain application in food supply information security," in the IEEE International Conference on Industrial Engineering and Engineering Management, (2018), 2017-December, pp. 13571361.

[23] P. W. Chen, B. S. Jiang, and C. H. Wang, "Blockchain-based payment collection supervision system using pervasive Bitcoin digital wallet," in 2017 IEEE 13th International Conference on Wireless and Mobile Computing, Networking and Communications (WiMob), (2017), pp. 139-146.

[24] N. Kshetri, "Blockchain's roles in strengthening cybersecurity and protecting privacy," Telecommun. Policy, vol. 41, no. 10, pp. 1027 1038, (2017).

[25] M. Nakasumi, "Information sharing for supply chain management based on blockchain technology," in 2017 IEEE 19th Conference on Business Informatics, CBI 2017, (2017), vol. 1, pp. 140-149.

[26] Z. Li, H. Wu, B. King, Z. B. Miled, J. Wassick, and J. Tazelaar, "On the Integration of Event-Based and Transaction-Based Architectures for Supply Chains," in the Proceedings - IEEE 37th International Conference on Distributed Computing Systems Workshops, ICDCSW 2017, (2017), pp. 376-382.

[27] K. Foerstl, M. C. Schleper, and M. Henke, "Purchasing and supply management: From efficiency to effectiveness in an integrated supply chain,” J. Purch. Supply Manag., vol. 23, no. 4, pp. 223-228, Oct. (2017).

[28] K. Leng, Y. Bi, L. Jing, H.-C. Fu, and I. Van Nieuwenhuyse, "Research on agricultural supply chain system with double chain architecture based on blockchain technology," Future Gener. Comput. Syst. Vol. 86, (2018), Pages 641-649.

[29] D. B. Kurka and J. Pitt, "Smart-CPR: SelfOrganisation and Self-Governance in the Sharing Economy," in 2017 IEEE 2nd International Workshops on Foundations and Applications of Self* Systems (FAS*W), (2017), pp. 85-90.

[30] B. Nicoletti, "The Future: Procurement 4.0," in Agile Procurement, Palgrave Macmillan, Cham, (2018), pp. 189-230.

[31] A. Imeri and D. Khadraoui, "The Security and Traceability of Shared Information in the Process of Transportation of Dangerous Goods," in 2018 9th IFIP International Conference on New Technologies, Mobility and Security (NTMS), (2018), pp. 1-5.

[32] K. Francisco and D. Swanson, "The Supply Chain Has No Clothes: Technology Adoption of Blockchain for Supply Chain Transparency," Logistics, vol. 2, no. 1, p. 2, Jan. (2018). 
[33] H. M. Kim and M. Laskowski, "Toward an ontology-driven blockchain design for supplychain provenance," Intell. Syst. Account. Finance Manag., vol. 25, no. 1, pp. 18-27, (2018).

[34] Archa, B. Alangot, and K. Achuthan, "Trace and track: Enhanced pharma supply chain infrastructure to prevent fraud," Lect. Notes Inst. Comput. Sci. Soc.-Inform. Telecommun. Eng. LNICST, vol. 218, pp. 189-195, (2018).

[35] S. Apte and N. Petrovsky, "Will blockchain technology revolutionize excipient supply chain management?," J. Excip. Food Chem., vol. 7, no. 3, pp. 76-78, (2016).

[36] W. Liu, S. S. Zhu, T. Mundie, and U. Krieger, "Advanced block-chain architecture for e-health systems," in 2017 IEEE 19th International Conference on e-Health Networking, Applications and Services (Healthcom), (2017), pp. 1-6.

[37] R. Beck, M. Avital, M. Rossi, and J. B. Thatcher, "Blockchain Technology in Business and Information Systems Research," Bus. Inf. Syst. Eng., vol. 59, no. 6, pp. 381-384, Dec. (2017).

[38] K. Jabbar and P. Bjørn, "Infrastructural Grind: Introducing Blockchain Technology in the Shipping Domain," in Proceedings of the 2018 ACM Conference on Supporting Groupwork, New York, NY, USA, (2018), pp. 297-308.

[39] S. Smetana, C. Seebold, and V. Heinz, "Neural network, blockchain, and modular complex system: The evolution of cyber-physical systems for material flow analysis and life cycle assessment," Resour. Conserv. Recycl., vol. 133, pp. 229-230, Jun. (2018).

[40] M. Ruta, F. Scioscia, S. Ieva, G. Capurso, and E. Di Sciascio, "Supply Chain Object Discovery with Semantic-enhanced Blockchain," in Proceedings of the 15th ACM Conference on Embedded Network Sensor Systems, New York, NY, USA, (2017), pp. 60:1-60:2.

[41] T. Bocek, B. B. Rodrigues, T. Strasser, and B. Stiller, "Blockchains everywhere - A use-case of blockchains in the pharma supply-chain," presented in the Proceedings of the IM 2017 - 2017 IFIP/IEEE International Symposium on Integrated Network and Service Management, (2017), pp. 772-777.

[42] Z. Gao, L. Xu, L. Chen, X. Zhao, Y. Lu, and W. Shi, "CoC: A Unified Distributed Ledger Based Supply Chain Management System," J. Comput. Sci. Technol., vol. 33, no. 2, pp. 237-248, (2018).

[43] L. Xu, L. Chen, Z. Gao, Y. Lu, and W. Shi, "CoC: Secure Supply Chain Management System Based on Public Ledger," in 2017 26th International Conference on Computer Communication and Networks (ICCCN), (2017), pp. 1-6.

[44] E. Hofmann, U. M. Strewe, and N. Bosia, "Concept-Where Are the Opportunities of Blockchain-Driven Supply Chain Finance?," in Supply Chain Finance and Blockchain Technology, Springer, Cham, (2018), pp. 51-75.

[45] E. Hofmann, U. M. Strewe, and N. Bosia, "Conclusion-What Can We Learn from
Blockchain-Driven Supply Chain Finance?," in Supply Chain Finance and Blockchain Technology, Springer, Cham, (2018), pp. 89-91.

[46] E. Hofmann, U. M. Strewe, and N. Bosia, "Discussion-How Does the Full Potential of Blockchain Technology in Supply Chain Finance Look Like?," in Supply Chain Finance and Blockchain Technology, Springer, Cham, (2018), pp. 77-87.

[47] E. Hofmann, U. M. Strewe, and N. Bosia, "Introduction-Why to Pay Attention on Blockchain-Driven Supply Chain Finance?," in Supply Chain Finance and Blockchain Technology, Springer, Cham, (2018), pp. 1-6.

[48] D. E. O'Leary, “Configuring blockchain architectures for transaction information in blockchain consortiums: The case of accounting and supply chain systems," Intell. Syst. Account. Finance Manag., vol. 24, no. 4, pp. 138-147, (2017).

[49] S. van Engelenburg, M. Janssen, and B. Klievink, "Design of a software architecture supporting business-to-government information sharing to improve public safety and security," J. Intell. Inf. Syst., pp. 1-24, Jul. (2017).

[50] K. Korpela, J. Hallikas, and T. Dahlberg, "Digital Supply Chain Transformation toward Blockchain Integration," Hawaii Int. Conf. Syst. Sci. 2017 HICSS-50, Jan. (2017).

[51] Z. C. Kennedy et al., "Enhanced anti-counterfeiting measures for additive manufacturing: Coupling lanthanide nanomaterial chemical signatures with blockchain technology," J. Mater. Chem. C, vol. 5, no. 37, pp. 9570-9578, (2017).

[52] Y. Madhwal and P. B. Panfilov, "Industrial Case: Blockchain on Aircraft's Parts Supply Chain Management," in American Conference on Information Systems 2017 Workshop on Smart Manufacturing Proceedings. 6. (2017). 